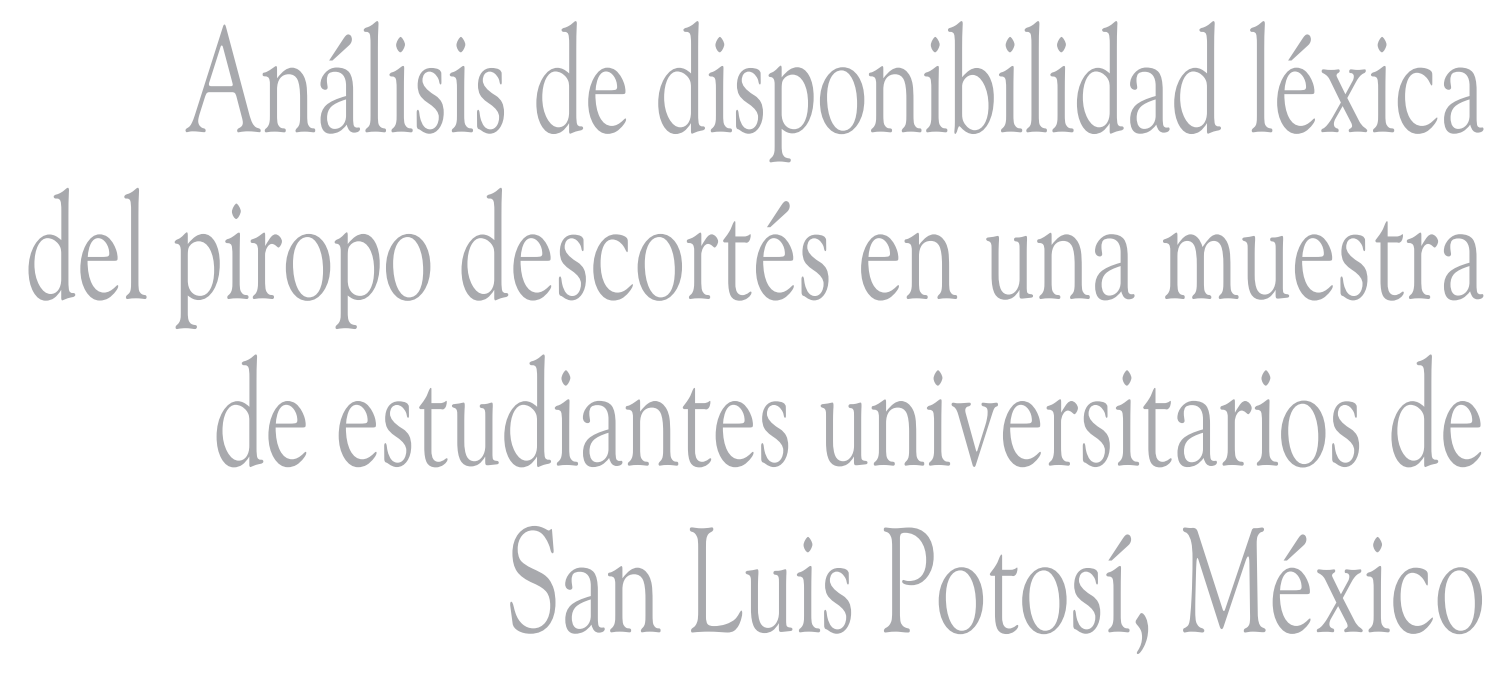

LEXICAL AVAILABILITY ANALYSIS OF THE OFF-COLOR COMPLIMENT in a sample of university students from San Luis Potosi, Mexico

\title{
Marco Antonio Pérez-Durán*
}

* Universidad Autónoma de San Luis Potosí, México

Correo-e: marco.duran@uaslp.mx (D) https://orcid.org/0000-00030854-3109

Recibido: 13 de febrero de 2019

Aprobado: 13 de mayo de 2019
Resumen: Se estudia el piropo descortés desde el ámbito de la disponibilidad léxica en estudiantes universitarios de la ciudad de San Luis Potosí, México. La metodología utilizada fue una encuesta en la que se pidió a 600 estudiantes universitarios (300 hombres y 300 mujeres) escribir los piropos descorteses que conocían. Con la información obtenida se hizo una clasificación estadística de la muestra por índice de disponibilidad léxica (IDL) y se organizó metafóricamente el piropo descortés.

Palabras clave: sociolingüística; español; México; cultura; lenguaje coloquial; violencia

Abstract: The off-color compliment is studied from the sphere of lexical availability in university students in the city of San Luis Potosi, Mexico. The methodology was a survey that asked 600 university students (300 men and 300 women) to write down the off-color compliments they knew. With this information, the statistical classification of the sample was carried out by lexical availability index (LAI), while off-color compliments were metaphorically organized.

Keywords: sociolinguistics; Spanish; Mexico; culture; colloquial language; violence 


\section{INTRODUCCIÓN}

En este artículo se presenta un estudio del piropo descortés desde el ámbito de la disponibilidad léxica en estudiantes universitarios de la capital de San Luis Potosí, México. Para ello, se hizo un análisis cuantitativo y otro cualitativo; en el primero se usó una fórmula matemática para detectar los piropos disponibles utilizados en una conversación, en el segundo se observó su construcción.

El piropo se considera: 1) una práctica discursiva, parte del folklor de una comunidad que lo valida y actualiza; 2) una práctica social utilizada por cualquier hablante, sin importar su estatus ni condición socioeconómica; 3) un acto de habla en términos socio-discursivos (Searle, 1980; Austin, 1982); 4) un terreno argumentativo que contiene estrategias de cortesía y descortesía verbal que afectan la imagen pública (Brown y Levinson, 1978); 5) en función de la interacción discursiva puede ser cortés o descortés. Este último es el que se analiza en este trabajo. El piropo cortés cumple una función apreciativa cuya finalidad es mostrar afecto y admiración hacia su destinatario(a), mientras que en el descortés las alabanzas no son agradables ni sutiles, todo lo contrario, son agresivas y usan estructuras discursivas callejeras que lo fortalecen.

En cuestión estadística, el Corpus Diacrónico del Español (CORDE) (Real Academia Española, 2019) señala 29 casos del piropo descortés, que representan $6.6 \%$ para México de un promedio de 340 registros. Este es un porcentaje muy bajo si se observa que, en el registro del piropo, no es fácil contar con datos que realmente muestren la dinamicidad con la que aparece en las conversaciones. Tradicionalmente, el piropo es un acto eventual de tipo descortés que presenta el cuerpo como un terreno sexual explorable con un dueño establecido, en este caso el emisor.

Antiguamente, el piropo era considerado un halago o lisonja encaminado a establecer o mantener una interacción comunicativa entre una mujer y un hombre de forma agradable. Con el paso del tiempo se modificó hasta llegar a lo descortés. Este tipo de piropos también es conocido como 'antipiropo' (Rodríguez Alfano, Flores Treviño y Jiménez Martín, 2008; Pericchi Pagá, 2011; Rodemann, 2015), 'piropo callejero' (Carvajal Ríos, 2014; Arancibia, Billi, Bustamante, et al., 2015) o 'piropo vulgar' (Schreier, 2005).

La tarea fundamental de la descortesía es humillar, sobajar o denigrar a la persona que recibe el piropo, mediante comentarios hirientes que se encuentran en el juego de palabras utilizados en la interacción. Su resultado es un atentado contra la imagen social o pública, así como individual del afectado, en este caso, una mujer. Quien usa el piropo manifiesta un estado pleno de conocimiento de la agresión que genera y del impacto social disfrazado de disgusto de quien lo recibe (Haverkate, 2004; Schreier, 2005).

El estudio del piropo no es privativo de una disciplina, por ejemplo, en lingüística se ha analizado desde los ámbitos de la socio-pragmática y de la lingüística cognitiva (construcción de la metáfora). Dentro de la primera, es relevante el trabajo de Achugar (2001), así como el de Flores Cuellar y Feria Arroyo (2018). El primero recoge un corpus de piropos de México, España, El Salvador, Argentina y Puerto Rico. Al analizar la muestra, la autora descubrió que el piropo es una práctica discursiva relacionada con la tradición cultural de tratamiento cortés de hombres hacia mujeres en las culturas hispanas. La otra investigación referida es más reciente y versa sobre el piropo como práctica cultural de las y los jóvenes en la ciudad de León, Guanajuato, en México. Aquí, los datos indican que los informantes construyen el piropo de diferente forma a partir del cuerpo, el género y el espacio sociodemográfico de los informantes. En el terreno de la lingüística cognitiva, los artículos de Ribas y Todolí (2008) y el de Martín García (2017) son referentes en la discusión y análisis de los piropos del tipo descortés. El primero analiza el cuerpo femenino como 
objeto y su reiteración en la publicidad, mientras que el segundo estudia el piropo a partir de la metáfora, para ello usa el Corpus del Proyecto para el Estudio Sociolingüístico del Español de España y de América (PRESEEA).

Lo relevante y novedoso del estudio que ahora presentamos es que descubre un nuevo punto de interés, ampliando la lista de trabajos recientes, que toma en consideración la fórmula matemática de disponibilidad léxica para ponderar los piropos con mayor disponibilidad y así observar su variación entre hombres y mujeres.

En esta investigación, el piropo descortés forma parte del centro de interés 'la seguridad-inseguridad', que ya se ha descrito en el trabajo de Wingeyer (2014) sobre los mitos populares, la ciudad, el campo, los insultos y las diversiones nocturnas. En lo que se refiere al contexto potosino, el estudio del piropo descortés es algo que no se ha realizado en ningún ámbito social porque, al igual que en otras partes, su uso está estigmatizado y se limita, principalmente, al contexto estudiantil en el que la dinámica conversacional es coloquial y abundante. Por esta razón, analizamos el piropo descortés en el contexto académico universitario.

\section{METODOLOGíA}

Se aplicó una encuesta a 600 estudiantes universitarios de la capital potosina (300 hombres y 300 mujeres), sin importar si pertenecían a universidades públicas o privadas ni su edad. Para recolectar la información, se visitaron las universidades del área metropolitana y se aplicaron los cuestionarios a los alumnos de manera espontánea. La encuesta requería el conocimiento de los informantes sobre el piropo descortés; para ello, la indicación que se les dio fue la siguiente: "Escriba todos los piropos descorteses que usted conozca". Esta directriz se usa con frecuencia en los trabajos de disponibilidad léxica ya que sirve de estímulo para que el encuestado procese la información solicitada y empiece a responder el cuestionario.

El tiempo destinado para completar la encuesta fue de tres minutos. ${ }^{1}$ El procesamiento metodológico de las respuestas se llevó a cabo del siguiente modo: la información obtenida se capturó en un procesador de textos y se aplicó el proceso de igualación ortográfica consistente en la corrección, tanto de forma como de contenido, para obtener los vocablos generados por los informantes. La base de datos se obtuvo durante doce meses (todas las muestras corresponden al periodo 2015-2016). Una vez hecha la corrección idiomática se procedió a la aplicación de la fórmula matemática que se usa en este tipo de pruebas para contar con la muestra de los piropos descorteses organizados de acuerdo con el índice de disponibilidad léxica (IDL). Hecho el análisis estadístico se ordenó la muestra a partir de la metáfora y se ubicaron los ejemplos de acuerdo con los resultados.

\section{MARCO TEÓRICO}

En la última década se han incrementado notablemente las investigaciones sobre violencia sexual, en específico verbal, la cual incluye conductas transgresoras que, a simple vista, se observan en cualquier contexto sociocultural y son aceptadas porque se ubican dentro de la interacción comunicativa. Aunque son comportamientos lingüísticos que contravienen las reglas de la cortesía verbal, su uso es prolífico en cualquier medio escolar (Cava y Musitu, 2002).

Schreier (2005) afirma que todavía no existe una opinión científica unánime acerca de qué es el piropo, qué papel comunicativo tiene entre los

1 La metodología que se emplea en la asignación del tiempo está altamente comprobada en los trabajos de disponibilidad léxica. Este lapso permite al informante abstraer del interior al exterior la realidad lingüística con la que se va a trabajar. 


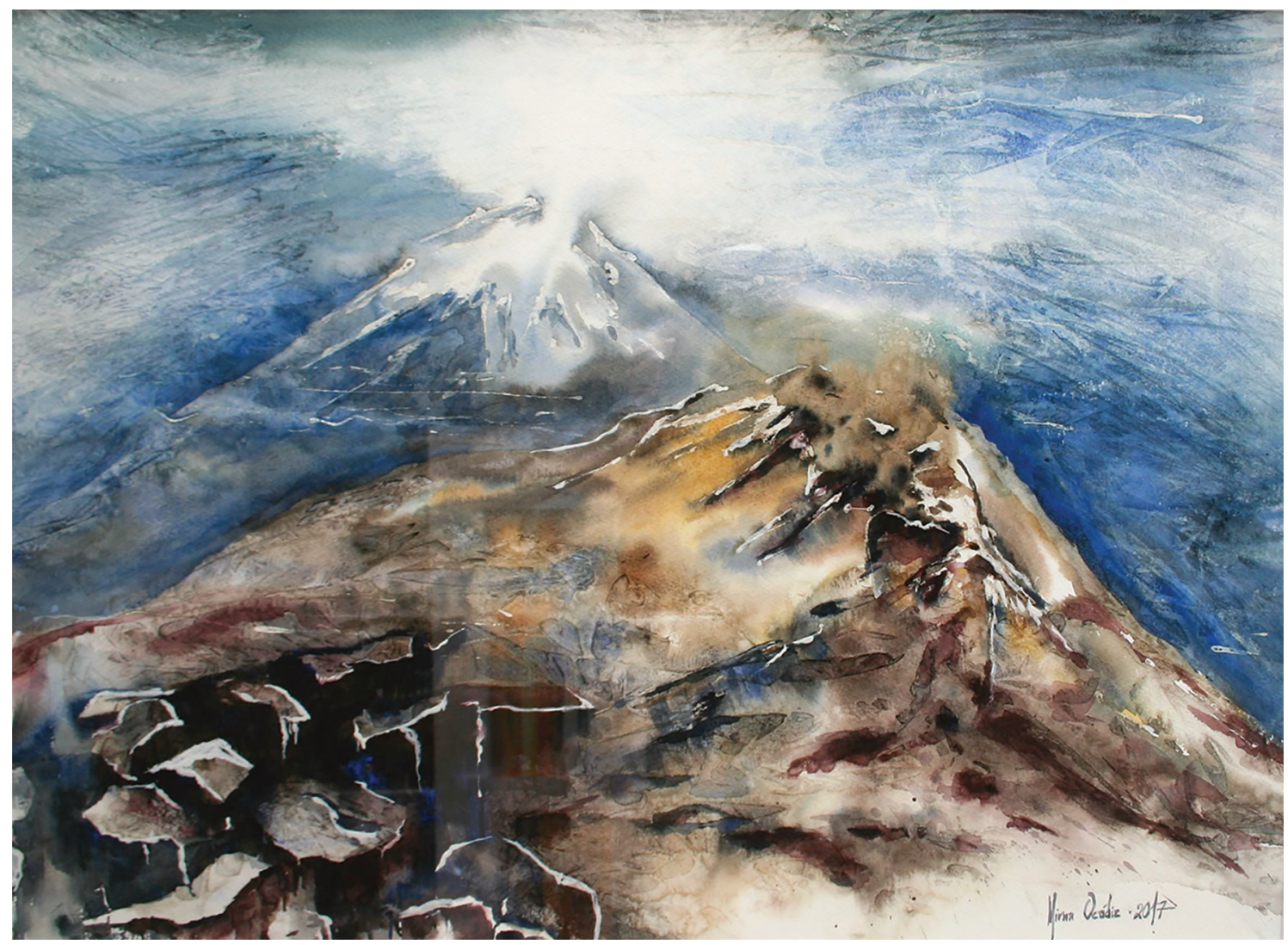

Volcanes (2017). Acuarela sobre papel de algodón: Mirna Ocádiz-Soto.

Prohibida su reproducción en obras derivadas.

sexos y cuál es su función. Lo único que se conoce es que, antiguamente, contenía características poéticas y pintorescas en el mensaje que enfatizaban costumbres socioculturales corteses y, en la cultura hispánica, era considerado una práctica en la que se alababan los atributos físicos de la mujer.

Según Haverkate (2004), la aportación española más auténtica al inventario de los cumplidos es el piropo, no obstante, con el tiempo fue adquiriendo nuevos valores semánticos que transformaron su sentido original hasta llegar a los significados descorteses de la actualidad. Así pues, pasó de tener un carácter poético a ser una expresión verbal altisonante, callejera, producida y utilizada generalmente por hombres hacia mujeres, aunque en el presente también los afecta a ellos. Su significado ha cambiado para referirse a partes del cuerpo y al acto sexual, principalmente, reforzando la imagen positiva de quien los usa ante su grupo social con una finalidad negativa (Ribas y Todolí, 2008: 153-169). De igual forma, presenta una estructura sociocultural altamente productiva que se refleja en el discurso cotidiano de los jóvenes.

Cuando se usa el piropo, sus consecuencias pueden ser la afectación de la imagen del otro, su vulnerabilidad emocional y bajeza, entre otras (Johnstone, 2005). Así, presenta una estructura invariable en todos los sentidos; constituye la emisión de un mensaje unidireccional con un tono coloquial y no solicitado, dirigido de un hablante del sexo masculino hacia una oyente del sexo femenino con la que no tiene ninguna relación o cuya relación aún no es profunda o estrecha (Gutiérrez Rivas, 2014: 45-64).

A la unidireccionalidad se le suma la bidireccionalidad. Ambas forman parte de la construcción del mensaje, pero solamente la primera se da en el piropo. Esta característica consiste en 
observar la ejecución del mensaje a través de la fuente, es decir, al emitir el mensaje se genera un acto de habla que no presenta una respuesta por parte del emisor porque es indirecto, como se aprecia en el siguiente ejemplo:

\section{H1. ${ }^{2}$ Bonitas piernas, ¿a qué hora abres?}

Aquí se observa que 'las piernas' son dos puertas que impiden el paso a la diversión y se ve esta parte del cuerpo como un objeto, lo cual se refleja cuando se hace la pregunta del horario de servicio. Baralo (2007) afirma que se pueden considerar los usos del piropo como un subcomponente textual que, a nivel productivo y receptivo, genera estrategias de comunicación específicas que cumplen con el propósito establecido; es claro y puntual y su significado es específico e indirecto, por lo que no existe ninguna ambigüedad de significado, quien lo usa conoce el coste-beneficio que puede tener como resultado.

Por el contrario, en la bidireccionalidad existe un inicio y un término del mensaje que rompe con la estructura del piropo; es una característica de los discursos tradicionales que se enuncian todos los días: a toda emisión le corresponde una respuesta, en caso contrario el mensaje es considerado descortés. La diferencia más importante con el piropo que analizamos es que en el mensaje tradicional los temas no son tabú y no se enuncian indirectamente. Así, los roles están claramente identificados, como se aprecia a continuación:

\section{H1. iQué bonitas piernas tienes!}

M1. Muchas gracias, Juan, ino se ven gordas con esta falda?

En este ejemplo hay dos participantes claramente definidos por los roles que cumplen (emisor-receptor). Existe una respuesta positiva a la emisión de H1 a M1, en el sentido de que no

2 Las letras corresponden a los emisores $\mathrm{H}$ hombre y $\mathrm{M}$ mujer. hay daño a la imagen pública porque se acepta el comentario referido a una parte del cuerpo. La apertura y el cierre del mensaje es una característica de la bidireccionalidad y la aceptación de éste se da en la misma interacción. De acuerdo con Gutiérrez Rivas (2014: 45-64), el piropo es una estrategia que apunta mayoritariamente hacia la seducción y forma parte de los rituales del cortejo. Su estructura es altamente productiva en las culturas en las que la sexualidad sigue siendo un tabú, como en el caso del mundo hispánico. El mensaje (y principalmente el léxico) tabuizado, cargado de contenido vulgar y gráfico, está presente en el piropo y solamente aparece en la metáfora. Ésta es considerada una práctica oral que se lleva a cabo en el espacio público mediante el deseo agresivo y denigrante del hombre hacia el cuerpo de la mujer como mecanismo de proyección insultante (Suárez Orozco y Dundes, 1999: 146).

Como ya se sabe, la metáfora es un recurso lingüístico-cognitivo que valida la transgresión de las normas socioculturales (Cuenca y Hilferty, 1999; Gutiérrez Rivas, 2014; Venclovská, 2006), lo cual se aprecia en el piropo. ¿Cómo se construye ese significado? La metáfora es un concepto sistemático que estructura nuestros pensamientos mediante la idealización de las acciones expresadas por medio de una realidad diferente, proyectando así una relación de semejanza entre el objeto expresado y su realidad enunciada. Ésta es la característica principal del piropo, una irrealidad dentro de la realidad expresada.

Lakoff y Johnson (1980) fueron los pioneros en este ámbito de investigación y clasificaron las metáforas en tres grupos: 1) orientacionales, 2) ontológicas y 3) estructurales. Las primeras son aquellas que sistematizan una red global de conceptos en relación con otros y nacen de nuestra interacción con el mundo físico. Están vinculadas con la orientación espacial: arriba/abajo, derecha/izquierda, dentro/fuera, delante/detrás, profundo/superficial, central/periférico. Las ontológicas categorizan un fenómeno de forma 
peculiar, es decir, lo ven como una entidad, sustancia, recipiente, individuo, etcétera, para tomar sus rasgos constitutivos más concretos y tangibles. Las estructurales organizan una actividad o noción en términos de otro; en este grupo existe una metáfora central (por así decirlo) de la que se generan otras que sirven para explicar aspectos parciales de metáforas consistentes con la inicial. Así, por medio de la metáfora estructural se entiende un dominio de la experiencia mediante la proyección de los elementos de origen a los dominios de destino.

En este artículo, el piropo descortés estudiado, producto de las respuestas de los universitarios, sienta su base en la metáfora estructural y en la ontológica que, a su vez, utiliza el concepto del cuerpo de la mujer del siguiente modo: 1) el cuerpo y el acto sexual como comida; 2) el cuerpo como recipiente; 3) el cuerpo como objeto; 4) el cuerpo como actividad económica. Para ello el piropo, además de la metáfora, utiliza el léxico sexuado, el cual consiste en aquellos vocablos tabuizados que culturalmente no son aceptados porque transgreden las normas sociales y culturales del grupo, por lo que se llega a incluirlos dentro de lo estigmatizado (Suárez Orozco y Dundes, 1999; Venclovská, 2006). Como ejemplo se usa el piropo descortés. 'Estoy cojo pero rico', en el que se intuye el significado del léxico sexual, es decir, se hace referencia al vocablo 'pene', a la acción que se genera al utilizarlo y a la idea de que esta actividad se realiza bien. Por formar parte de un léxico sexual, la accesibilidad al usarlo y aplicarlo es alta; y al ser el piropo del tipo descortés se nutre de este vocabulario (Ávila Muñoz, 2016: 31-43).

En lo referente al análisis estadístico del léxico sexual, no existen trabajos que expongan mediante la léxico-estadística cuáles son los vocablos peyorativos ni mucho menos otro tipo de estructuras metafóricas que contienen ese vocabulario, como los piropos. Contar con una descripción de este tipo ayudará a que el léxico disponible sirva de base para entender los nuevos procesos comunicativos y las relaciones entre los informantes; es más, tener una muestra confiable servirá para mejorar la descripción de la lengua y permitirá planificar lo que se quiera enseñar. En suma, la amplitud de estudios y resultados que se están llevando a cabo deja ver que todavía hace falta mucho trabajo léxico-estadístico sobre el vocabulario disponible. Lo hecho hasta el momento afianza la necesidad de ampliar el análisis de las comunidades lingüísticas y los estratos sociales en su diacronía y sincronía. Así, tal vez se pueda llegar a conocer el vocabulario panhispánico que se pretende. De esta forma, los léxicos disponibles son considerados el reflejo del caudal de vocablos que los hablantes usamos en determinadas situaciones comunicativas (Ávila Muñoz y Sánchez Sáez, 2011).

\section{ANÁLISIS DEL CORPUS}

Al revisar la muestra, el número de piropos que se obtuvo de los cuestionarios (sin depurar) aplicados a 600 estudiantes universitarios de la capital potosina fue de 1173 expresiones, divididas en 655 ocurrencias de hombres y 518 de mujeres. Al realizar la corrección ortográfica de los cuestionarios y aplicar la fórmula de disponibilidad léxica, el número de piropos fue 145, (12.36 \% de la totalidad) 76 de los cuales corresponden a hombres y 69 a mujeres. En palabras de Lopera Medina (2016), este porcentaje es un claro indicador del conocimiento que los hablantes de ambos géneros poseen de la información solicitada en cuanto a disponibilidad léxica.

Como se aprecia en el resultado general, las mujeres participantes en este proyecto conocen los piropos descorteses tanto como los varones. Con esto se rompe la idea de que solamente los hombres están familiarizados con estas estructuras, ya que tradicionalmente el piropo alude a la noción de poder que éstos tienen sobre la mujer. A partir de los resultados procesados se presenta la Tabla 1 con los veinte piropos más disponibles por índice de disponibilidad léxica (IDL).

Marco Antonio Pérez-Durán 
TABLA 1. Los VEINTE PIROPoS MÁs DISPonibleS

\begin{tabular}{|c|c|l|}
\hline & IDL & \\
\hline 1 & 0.5456 & En época de guerra cualquier hoyo es una trinchera \\
\hline 2 & 0.5366 & Estoy cojo pero rico \\
\hline 3 & 0.5256 & Mátame a pedos que quiero morir hediondo \\
\hline 4 & 0.5034 & Tú con esas tortas hasta mi pajarito canta \\
\hline 5 & 0.4798 & Vamos a hacer barbacoa, tú pones el animal y yo el hoyo \\
\hline 6 & 0.3658 & Te llenaré de mecánicos el taller \\
\hline 7 & 0.3484 & Al pan y vino y tu cola a mi pepino \\
\hline 8 & 0.3403 & Bizcocho, habrá quien te quiera bien y habrá quien te quiera mal, pero a mí aflójame tu tamal \\
\hline 9 & 0.3289 & Bonitas piernas, a qué hora abres \\
\hline 10 & 0.2994 & Si no hay Sico, por el hocico \\
\hline 11 & 0.2902 & Préstala panochambear \\
\hline 12 & 0.2855 & Me dijeron que te gusta hacer el chile pasilla \\
\hline 13 & 0.2793 & Hay que embarrarle el queso a los molletes \\
\hline 14 & 0.2692 & Con ese culo haz de cagar bombones \\
\hline 15 & 0.2482 & Tengo tanta leche que si no te hago un hijo te hago un queso \\
\hline 16 & 0.2472 & Con esa torta y un refresco eso y más merezco \\
\hline 17 & 0.2118 & Chiquita, con tu caca me hago un sope \\
\hline 18 & 0.2033 & iJugamos a la basurita? Tú te tiras y yo te recojo \\
\hline 19 & 0.1887 & Tu papaya está bien grande \\
\hline 20 & 0.1821 & Ninguna mujer es fea, si se le ve por dónde mea \\
\hline & & \\
\hline
\end{tabular}

Fuente: Elaboración propia.

El IDL que aparece al principio de la tabla es un valor mediante el cual es posible ordenar las palabras según la frecuencia y el orden de aparición -el grado de 'inmediatez' - con que los hablantes las actualizan (Callealta Barroso y Gallego Gallego, 2016). Además, constituye un indicador matemático para el vocabulario en el que 1 representa el valor más alto dentro de la muestra y es un referente numérico que trata de poner en relación criterios de frecuencia y orden. El cálculo en el que se basa pretende ponderar de manera adecuada la incidencia con la que se actualiza un vocablo en un centro de interés a partir de su posición en las diversas listas (Ávila Muñoz y Sánchez Sáez, 2011).

En la Tabla 1 todas las respuestas tienen connotación sexual. La más representativa para los
600 informantes fue: 'En época de guerra cualquier hoyo es una trinchera', referida a que cuando hay necesidad sexual cualquier mujer, particularmente cualquier vagina, está lista para la relación coital. Cuando la metodología de la disponibilidad léxica se aplica en una muestra se obtiene un mejor conocimiento de la situación en que se encuentra la comunidad, sin importar si se analiza un vocablo o una unidad mayor. Estos estudios aportan un sinfín de información sobre el vocabulario utilizado por los hablantes y con ello se pondera un IDL alto: 0.5456, $0.5366,0.5256$ y 0.5034 . Una ventaja es que los datos procesados se analizan desde diferentes puntos de vista, como presencia o ausencia de un vocablo determinado, neologismos, pérdida del léxico. En este caso, al ser el piropo un 
vocabulario tabuizado, el léxico que se presenta estadísticamente constituye una innovación al conocimiento de la lengua y la cultura de un grupo de informantes. Cuanto más alto sea el IDL mayor disponibilidad habrá en esa respuesta, así lo demuestran los cuatro primeros lugares en cuestión de la variable sexo (véase la Tabla 2). hoyo' está más relacionado con las respuestas disponibles de mujeres que de hombres.

En el análisis del léxico se han encontrado dos tipos de corpus: las muestras variables y las invariables. Las variables se presentan cuando entre las primeras diez contestaciones no existe relación entre una muestra y otra, ocasionando que

TABLA 2. LOS DIEZ PIROPOS DESCORTESES DISPONIBLES POR SEXO

\begin{tabular}{|c|c|c|c|c|}
\hline & IDL & Hombres & IDL & Mujeres \\
\hline 1 & 0.7347 & $\begin{array}{l}\text { En época de guerra cualquier hoyo es } \\
\text { una trinchera }\end{array}$ & 0.7336 & $\begin{array}{l}\text { En época de guerra cualquier hoyo es } \\
\text { una trinchera }\end{array}$ \\
\hline 2 & 0.5355 & Estoy cojo pero rico & 0.5456 & $\begin{array}{l}\text { Vamos a hacer barbacoa, tú pones el } \\
\text { animal y yo el hoyo }\end{array}$ \\
\hline 3 & 0.3849 & Te llenaré de mecánicos el taller & 0.4835 & Estoy cojo pero rico \\
\hline 4 & 0.3078 & $\begin{array}{l}\text { Tú con esas tortas hasta mi pajarito } \\
\text { canta }\end{array}$ & 0.3731 & $\begin{array}{l}\text { Mátame a pedos que quiero morir } \\
\text { hediondo }\end{array}$ \\
\hline 5 & 0.2662 & $\begin{array}{l}\text { Mátame a pedos que quiero morir } \\
\text { hediondo }\end{array}$ & 0.3557 & Al pan y vino y tu cola a mi pepino \\
\hline 6 & 0.2242 & Al pan y vino y tu cola a mi pepino & 0.3463 & $\begin{array}{l}\text { Tú con esas tortas hasta mi pajarito } \\
\text { canta }\end{array}$ \\
\hline 7 & 0.2187 & $\begin{array}{l}\text { Vamos a hacer barbacoa, tú pones el } \\
\text { animal y yo el hoyo }\end{array}$ & 0.3299 & Te llenaré de mecánicos el taller \\
\hline 8 & 0.1893 & $\begin{array}{l}\text { Bizcocho, habrá quien te quiera bien } \\
\text { y habrá quien te quiera mal, pero a mí } \\
\text { aflójame tu tamal }\end{array}$ & 0.3078 & $\begin{array}{l}\text { Ninguna mujer es fea, si se le ve por } \\
\text { dónde mea }\end{array}$ \\
\hline 9 & 0.1851 & Si no hay Sico, por el hocico & 0.2241 & Si no hay Sico, por el hocico \\
\hline 10 & 0.1835 & Bonitas piernas, a qué hora abres & 0.2218 & $\begin{array}{l}\text { Bizcocho, habrá quien te quiera bien } \\
\text { y habrá quien te quiera mal, pero a mí } \\
\text { aflójame tu tamal }\end{array}$ \\
\hline
\end{tabular}

Fuente: Elaboración propia.

Nótese cómo en el análisis de respuestas el IDL de la primera posición es el más alto con 0.7347 para hombres y 0.7336 para mujeres. La expresión más disponible por sexo es: 'En época de guerra cualquier hoyo es una trinchera', frase socialmente aceptada, al parecer, entre los jóvenes encuestados. En palabras de Venclovská (2006), esto rompe la idea de que solamente los varones tienen pleno conocimiento del vocabulario y el significado de las estructuras del piropo descortés, ya que las mujeres identifican este léxico socialmente aceptado y reconocido por parte de los informantes como un mensaje desagradable. De igual forma, el piropo 'Vamos a hacer barbacoa, tú pones el animal y yo el la diversidad de respuestas sea altamente inestable en el conocimiento del léxico-social. Las invariables son aquellas que no aportan diversidad entre las diez primeras posiciones. Esto produce una muestra cohesionada en la que la variedad es mínima, lo cual no permite que se incluyan nuevas respuestas en el corpus y ocasiona que los informantes repitan una y otra vez el mismo tipo de léxico. Al analizar la muestra encontramos un vocabulario cohesionado que no es diferente entre las variables a comparar, como se ha visto. En palabras de Murillo Rojas (1993), la información que pertenece al mismo grupo social y estrato socioeconómico muy pocas veces presenta variación. 
En la construcción de la metáfora interviene la noción de prototipo del vocabulario, que consiste en que el informante escoge la mejor respuesta para llenar el cuestionario. Dicha contestación es la que domina, por lo regular, las primeras posiciones, como se ve en el caso de las Tablas 1 y 2. Estas respuestas son las que los informantes han seleccionado de su repertorio léxico y social para que sean las más productivas. Así pues, una característica esencial de la selección léxica es el proceso de accesibilidad al vocabulario, que consiste en la manera en la cual ingresamos al repertorio de estructuras léxicas y en cómo entendemos que, a partir del centro de interés 'la seguridad y la inseguridad', se llega a ese repertorio. Una vez ahí se empieza a configurar la metáfora.

\section{AnÁLISIS DE LA METÁForA}

El piropo descortés es un fenómeno que influye en la sociedad y en las creencias; en combinación con ellas genera una interdicción lingüística, esto quiere decir que su realidad negativa prevalece en el aspecto social, al utilizarse un término tabuizado con una intención comunicativa bien establecida. En esta parte del artículo se hace la clasificación del piropo descortés desde la construcción metafórica.

\section{El cuerpo y el acto sexual como comida}

Es un tema recurrente, en el análisis del piropo descortés, considerar el acto sexual como comida (Correa Jiménez y Mancera Rodríguez, 2009; Gutiérrez Rivas, 2014; Maldonado Chamba, 2015). Alarcón Hernández (2002) menciona que las metáforas son posibles como expresiones lingüísticas, precisamente porque existen en nuestro sistema conceptual y, como tal, se manifiestan en la conducta cotidiana, pues son parte indispensable de nuestra forma convencional de representar el mundo. En ese sentido, el dominio meta del 'sexo' se da mediante la búsqueda y sistematización de expresiones provenientes del dominio de origen 'la comida' y esta relación propicia expresiones como: 'Quisiera ser aguacate para embarrarme en tu bolillo', 'Eres la carne de mis tacos', 'Tengo ganas de comerte', 'Al pan y vino y tu cola a mi pepino', 'Bizcocho, habrá quien te quiera bien y habrá quien te quiera mal, pero a mí aflójame tu tamal', 'Con esas tortas y una fanta hasta mi pajarito canta', 'Esa de verde, el chile que me muerde', 'Vamos a hacer barbacoa, tú pones el animal y yo el hoyo'.

\section{El cuerpo femenino como objeto}

Otras metáforas que forman parte del piropo descortés son aquellas que visualizan el cuerpo humano como un objeto, en las que se aprecia el deseo de poseerlo. En palabras de Martín García (2017: 49-65), este tipo de metáfora es la más generalizada y básica en nuestras comprensiones intelectuales, por lo que la cultura aparece recurrentemente ante nuestros ojos como una trama, un sistema, una estructura, una amalgama o, al menos, una colección de objetos. En consecuencia, el piropo forma parte de un patrimonio cultural en el que el ingenio y el juego de palabras hacen de este halago una expresión descortés. Así, 'En época de guerra cualquier hoyo es una trinchera', 'Nada más calientas el boiler y no te metes a bañar', 'Estoy cojo pero rico', 'Si no hay Sico por el hocico', 'Si nos queremos y nos amamos porque no juntamos por donde meamos', etcétera, son metáforas del cuerpo femenino como objeto, en las que se observa la proyección máxima idealizada del deseo imaginario masculino de deshumanizar a la mujer y hacer con ella lo que quiera (Morera Hernández, 2014).

\section{El cuerpo femenino como actividad económica}

Otra metáfora que se encontró en el análisis tiene que ver con la proyección del cuerpo femenino como actividad económica, por ende, redituable. 
Este tipo de figuras retóricas parte de la idea de que el cuerpo es un objeto del cual se obtienen beneficios mercantiles que pueden ser intercambiados en el plano sexual. Según Ribas y Todolí (2008: 153-169), se aprecian metáforas que han ido extendiéndose en sus dominios conceptuales y proyectan nuevas formas de ver el objeto metaforizado como mercadería. La idea de una 'mujer mercancía' tiene como particularidad el intercambio comercial. Esta noción, además, relaciona la acción económica con el informante. Como ejemplo de esto se observan los siguientes piropos: 'Quisiera ser mariachi para tocarte la cucaracha', 'Quisiera ser carpintero para clavarte mi clavo', 'Quisiera ser microbusero para subirte en la parada', 'Quisiera ser plomero para destaparte el agujero', 'Quisiera ser jardinero pa' regarte todo el día'. Aquí se puede notar cómo a la mujer se le representa metonímicamente por su capacidad de dar placer, mientras los informantes se relacionan con las profesiones 'mariachi', 'microbusero', 'plomero'.

\section{El cuerpo femenino como recipiente}

En la construcción del piropo descortés también se puede apreciar la idea del cuerpo como un recipiente que alberga todo tipo de cosas. Esta figura retórica se ubica en la clasificación de las metáforas ontológicas, que tienen como finalidad categorizar un fenómeno de forma peculiar mediante su consideración como entidad, sustancia, receptáculo. En palabras de Martín García (2017: 49-65), se debe considerar que cada uno de nosotros es un recipiente con una superficie limitada y una orientación dentro-fuera. Ésta es proyectada con respecto a otros objetos físicos que se encuentran en un determinado espacio. Ejemplo de ello son las expresiones: 'Te llenaré de mecánicos el taller', 'Naciste para llenarte el agujero de trabajadores', 'Te dejaré guardada en ese espacio la leche para que la conserves'.

\section{CONCLUSIONES}

En este análisis se trató de hacer una primera aproximación al estudio del piropo descortés en una muestra de estudiantes universitarios de San Luis Potosí. Al ser un trabajo pionero que describe dicho fenómeno en la población, se han establecido varios supuestos: uno de ellos es romper con la idea de que solamente los varones conocen los piropos descorteses. También se resalta la importancia de estudiar un fenómeno social muy dinámico y complicado de analizar desde la léxico-estadística y, por último, se enfatiza la organización conceptual de la metáfora.

Desde el ámbito de la léxico-estadística, se han presentado las diez respuestas más disponibles clasificadas por el IDL y el sexo de los informantes. De este análisis se dedujo que los IDL son parecidos tanto en hombres como en mujeres $(0.7347$ y 0.7336 , respectivamente) en cuanto al piropo: 'En época de guerra cualquier hoyo es una trinchera'. Sucede también con las respuestas: 'Estoy cojo pero rico', 'Mátame a pedos que quiero morir hediondo', 'Tú con esas tortas hasta mi pajarito canta', 'Vamos a hacer barbacoa, tú pones el animal y yo el hoyo', 'Te llenaré de mecánicos el taller', etcétera. Según los cuestionarios de disponibilidad léxica, estas expresiones son frecuentes en el argot estudiantil, que es diferente al de los adultos.

En lo referente a la estructuración conceptual del piropo descortés, la accesibilidad es una característica del vocabulario que permite obtener el léxico de tipo sexual requerido para la construcción metafórica. Este vocabulario es versátil y matiza el significado sexual y agresivo que genera el piropo descortés, estableciendo como base de su construcción y detonante conceptual el cuerpo femenino. De esta manera, se habla de la siguiente clasificación: 'el cuerpo como actividad económica', 'el cuerpo como objeto', 'el cuerpo como recipiente' y 'el cuerpo y el acto sexual 
como comida'. Las metáforas más productivas tienen que ver con este último grupo.

Finalmente, se sabe que el piropo descortés es una construcción dinámica que se inserta en la estructura social. Debido a esta característica, es muy difícil que se pueda localizar de forma interactiva, lo que se aprecia en los datos del CORDE. El problema fundamental del piropo descortés es que no es abierto sino discrecional y refiere la connotación sexual del emisor al receptor. En este artículo, el método de solicitud de información fue un referente claro para reconocer que el piropo descortés existe como tal, aunque hace falta estudiar su uso en contextos de oralidad que son fundamentales para tener una visión global de este fenómeno.

\section{REFERENCIAS}

Achugar, Mariana (2001), "Piropos as metaphors for gender roles in Spanish speaking cultures", Pragmatics. Quarterly Publication of the International Pragmatics Association (IPrA), vol. 11, núm. 2, pp. 127-137.

Alarcón Hernández, Paola (2002), "El acto sexual es comer: descripción lingüístico-cognitiva", Revista de Lingüística Teórica y Aplicada (RLA), núm. 40, pp.7-24.

Arancibia, Javiera, Marco Billi, Camila Bustamante et al. (2015), Acoso sexual callejero: contexto y dimensiones, Santiago de Chile, Observatorio Contra el Acoso Callejero.

Austin, J. L. (1982), Cómo hacer cosas con palabras, Buenos Aires, Paidos Studio.

Ávila Muñoz, Antonio Manuel (2016), "El léxico disponible y la enseñanza del español. Propuesta de selección léxica basada en la teoría de los conjuntos difusos", Journal of Spanish Language Teaching, vol. 3, núm. 1, pp. 31-43.

Ávila Muñoz, Antonio Manuel y José María Sánchez Sáez (2011), "La posición de los vocablos en el cálculo del índice de disponibilidad léxica: procesos de reentrada en las listas del léxico disponible de la ciudad de Málaga", Estudios de Lingüística (ELUA), núm. 25, pp. 45-74.

Baralo, Marta (2007), "Adquisición de palabras: redes semánticas y léxicas", en Actas del Foro de español internacional: Aprender y enseñar léxico, pp. 384-399.

Brown, Penelope y Stephen C. Levinson (1978), "Universals in language-usage: politeness phenomena. Questions and politeness", en Esther N. Goody (ed.), Questions and Politeness: Strategies in Social Interaction, Cambridge, Cambridge University Press, pp. 56-311.

Callealta Barroso, Francisco Javier y Diego Javier Gallego Gallego (2016), "Medidas de disponibilidad léxica: comparabilidad y normalización", Boletín de Filología, vol. 51, núm. 1, disponible en: https://scielo. conicyt.cl/scielo.php?script $=$ sci_arttext $\&$ pid $=$ S0718 $93032016000100002 \& \operatorname{lng}=\mathrm{en}_{\mathbf{1}} \overline{\mathrm{n}} \mathrm{rm}=\mathrm{iso} \& \mathrm{t} \operatorname{lng}=\mathrm{en}$

Carvajal Ríos, Sofía (2014), El piropo callejero: acción política y ciudadana, tesis de maestría, Quito, Universidad Andina Simón Bolívar.

Cava, María Jesús y Gonzalo Musitu (2002), La convivencia en la escuela, Madrid, Paidós Ibérica.

Correa Jiménez, Nataly y Jennifer Andrea Mancera Rodríguez (2009), La práctica del piropo en los trabajadores de la construcción que laboran en la ciudad de Bogotá, tesis de licenciatura, Bogotá, Pontificia Universidad Javeriana.

Cuenca, María Josep y Joseph Hilferty (1999), Introducción a la lingüística cognitiva, Barcelona, Ariel.

Flores Cuellar, Brenda Fayrut y Demetrio Arturo Feria Arroyo (2018), "Representaciones y prácticas culturales en jóvenes en León, Guanajuato. El caso del piropo en las y los jóvenes", Jóvenes en la Ciencia. Revista de Divulgación Científica, vol. 4, núm. 1, pp. 1314-1318.

Gutiérrez Rivas, Carolina (2014), “Consideraciones sobre el piropo en Venezuela desde las nociones de imagen y ethos, de la Teoría de la Cortesía”, Moderna Språk, vol. 108, núm. 2, pp. 45-64.

Haverkate, Henk (2004), La cortesía verbal. Estudio pragmalingüístico, Madrid, Gredos. 
Johnstone, Barbara (2005), Discourse Analysis, Malden, Blackwell.

Lakoff, George y Mark Johnson (1980), "The Metaphorical Structure of the Human Conceptual System", Cognitive Science, vol. 4, núm. 2, pp. 195-208.

Lopera Medina, Sergio (2016), Análisis sociopragmático de los cumplidos en una población universitaria en Medellín, Colombia, tesis doctoral, Medellín, Universidad de Antioquía.

Maldonado Chamba, Amaranta Cecilia (2015), Análisis comunicacional del piropo como fenómeno social de violencia de género en la ciudad de Quito, tesis de licenciatura, Quito, Universidad Politécnica Salesiana.

Martín García, Lorena (2017), "Aproximación a las metáforas de la vida cotidiana en el corpus PRESEEA de Granada”, Verbeia, año III, núm. 2, pp. 49-65.

Morera Hernández, Coral (2014), "Mujer, violencia y cine: la agresión masculina como estrategia narrativa", Prisma Social: Revista de Investigación Social, núm. 13, pp. 257-287.

Murillo Rojas, Marielos (1993), "Disponibilidad léxica en los preescolares: estudio de cinco campos semánticos", Káñina, vol. XVII, núm. 2, pp. 117-127.

Pericchi Pagá, Natalia (2011), "GonzÁlez, Carla Margarita. 2009. Si así eres en rayas cómo serás en Pelotas. Piropos y antipiropos caraqueños. Caracas: Fundación para la cultura urbana. 120 pp”, Boletín de Lingüística, vol. XXIII, núm. 3536, pp. 205-212.

Real Academia Española (2019), Corpus Diacrónico del Español (CORDE), disponible en: http://corpus.rae.es/cordenet.html

Ribas, Monserrat y Júlia Todolí (2008), "La metáfora de la mujer objeto y su reiteración en la publicidad", Discurso $\mathbb{E}$ Sociedad, vol. 2, núm. 1, pp. 153-169.

Rodemann, Helena (2015), "Derechos en conflicto: una ley anti-piropo en España", Cuestiones de Género: de la Igualdad y la Diferencia, núm. 10, pp. 151-160, disponible: http:// dx.doi.org/10.18002/cg.v0i10.1513.

Rodríguez Alfano, Lidia, María Eugenia Flores Treviño y Elena Jiménez Martín (2008), "Lo cortés no quita lo directo. La petición y la ironía en el habla de Monterrey”, en III Coloquio Internacional del programa EDICE "Cortesía y conversación: de lo escrito a lo oral", pp. 209-317.

Searle, John R. (1980), Actos del Habla. Un ensayo de filosofía del lenguaje, Madrid, Cátedra.

Suárez-Orozco, Marcelo M. y Alan Dundes (1999), "Una interpretación psicocultural del piropo en América Latina”, en Martha Blache (comp.), Folklore urbano. Vigencia de la leyenda y los relatos tradicionales, Buenos Aires, Ediciones Colihue, pp. 143-154.

Schreier, Judith (2005), "Quién fuera mecánico... Un estudio sociopragmático sobre la aceptación social del piropo”, Revista Internacional de Lingüística Iberoamericana, vol. 3, núm. 5, pp. 65-78.

Wingeyer, Hugo Roberto (2014), "Temas de la disponibilidad léxica de la región NEA de Argentina: mitos populares, la ciudad, el campo, insultos y diversiones nocturnas. Aportes para la elaboración de programaciones interculturales y de materiales en la enseñanza de E/LE”, Signos ELE, núm. 8, pp. 1-14.

Venclovská, Natálie (2006), Los piropos españoles, tesis doctoral, Brno, Masarykova univerzita.
Marco Antonio Pérez Durán. Doctor en Lingüística por la Universidad Nacional Autónoma de México (UNAM), México, y catedrático de Lengua Española en la Facultad de Ciencias Sociales y Humanidades y en la Facultad de Psicología de la Universidad Autónoma de San Luis Potosí (UASLP), México. Su investigación se ha centrado fundamentalmente en lexicología, fraseología, palabras tabú o altisonantes, disponibilidad léxica, violencia escolar, enseñanza de la lengua materna y análisis del discurso desde la socio-pragmática. En estos ámbitos ha publicado el artículo "Un estudio sobre los macrocentros de interés (McI). Una aportación teórica para los estudios actuales de disponibilidad léxica" (Cuadernos de Lingüística de El Colegio de México, vol. 6, núm. 1). 